Department at the Hebrew University, Jerusalem. The Unit's functions are ( $\mathrm{I}$ ) initiation, co-ordination, and supervision of research into subjects relating to historical, anthropological, sociological, economic, geographical, political, or international aspects of African development; (2) construction of a documentation centre dealing with African subjects; (3) publication of scholarly works in the field of African studies, and organization of conferences and study seminars.

Research projects now being carried out by the Africa Research Unit include: Islam as a Political Factor in Africa (Professor N. Levtzion); Separatism and Self-Determination (Dr. D. Ronen); The Strategic Significance of the Red Sea Gulf (Dr. M. Abir); The Israeli Experience in Africa: a Follow-up Study of 500 Israeli Experts who served in Africa (Mrs. N. Chazan). The Truman Institute Library is receiving many periodicals dealing with African subjects and collecting government publications and other items of documentation; a catalogue of library holdings is available. The Africa Research Unit has also initiated a newspaper indexing and clipping service including major African, Israeli, and international dailies and covering a wide range of subjects of African concern. The Unit has just published the proceedings of a conference on Israel and the Ivory Coast; study seminars have been held during the current academic year and a conference on "Africa in the Seventies and the Eighties' is being planned for the spring of 1974 .

Further information on the activities and publications of the Africa Research Unit may be obtained from the Co-ordinator, Dr. Dov Ronen.

\title{
Black Studies at the University of Puerto Rico, Rio Piedras Campus
}

FrOM 1970 to 1971 the University of Puerto Rico has been offering the following courses at its Rio Piedras Campus: 'The Negro in Puerto-Rican literature' at the Faculty of Estudios Generales, by Professor Isabelo Zenón Cruz, from 1970; 'The Negro in Universal Poetry', a course started in 197 I by Professor Pini Fernández de Lewis at the Faculty of Humanities (Arts); 'The Experience of the North-American Negro in Literature', from 1971, by Professor Jubilee, also at the Faculty of Humanities.

\section{(Communicated by Professor Luis Beltrán, Afro-Hispanic Studies Group)}

\section{Santo Domingo Symposium on the African Presence in the Caribbean Area}

ORGANIZED by the Department for Scientific Research of the Autonomous University of Santo Domingo (UASD), a Symposium on the African Presence in the Caribbean Area took place in Santo Domingo (Dominican Republic) from 26 July to 4 August 1973. Delegates from the Dominican Republic, Jamaica, Ghana, Haiti, Puerto-Rico, Senegal, Spain, Trinidad, United States, Venezuela, and Zaire attended this meeting. The papers dealt mainly with the origin of African presence in the Caribbean area, the influence of this presence in the national culture of these American countries and the results will be published in a volume of the UASD. Professor Franklin J. Franco, Director for Scientific Research, UASD, was in charge of the co-ordination at this Symposium.

\section{Communicated by Professor Luis Beltrán, Afro-Hispanic Studies Group)}

\section{International Symposium on Authenticity (National University of Zaïre. Lubum- bashi Campus)}

This Symposium organized under the patronage of the President of the Republic of Zaire and the UNAZA, Lubumbashi Campus, will take place in May 1974 at Lubumbashi. The principal object will be to define the concept of 'authenticité' that is to say, the cultural 